\title{
PENGETAHUAN DAN TINDAKAN PEMERIKSAAN PAYUDARA SENDIRI (SADARI) PADA REMAJA PUTRI DI SMK NEGERI 07 MEDAN TAHUN 2016
}

\author{
Yufdel, Dina Indarsita, Nurul Azizah \\ Jurusan Keperawatan Poltekkes Kemenkes Medan
}

\begin{abstract}
Abstrak
Remaja merupakan masa peralihan dari masa kanak-kanak menuju dewasa. Salah satu organ yang berkembang pada remaja khususnya wanita adalah payudara. Pemeriksaan payudara sendiri merupakan salah satu langkah awal deteksi dini untuk menemukan kanker payudara stadium awal yang akan lebih efektif jika dilakukan sedini mungkin, sebab $85 \%$ kelainan payudara justru pertama kali dikenali oleh penderita. Tujuan pemeriksaan payudara sendiri (SADARI) adalah untuk mengetahui adanya kelainan pada payudara sejak dini. Tujuan penelitian ini adalah untuk mengetahui gambaran pengetahuan dan tindakan pemeriksaan payudara sendiri (SADARI) pada remaja putri di SMK Negeri 07 Medan. Jenis penelitian yang dilakukan adalah penelitian deskriptif. Pada penelitian ini jumlah populasi adalah seluruh siswi kelas X jurusan administrasi di SMK Negeri 07 Medan sebanyak 204 orang dan yang menjadi sampel yaitu sebanyak 40 orang. Teknik pengambilan sampel dengan menggunakan teknik simple random sampling. Pengumpulan data dilakukan dengan menggunakan kuesioner. Analisis data dilakukan dengan mencari proporsi pada tindakan dan pengetahuan tentang pemeriksaan payudara sendiri pada remaja putri. Hasil penelitian yang dilakukan pada 40 orang responden diperoleh ada 22 orang (55\%) responden yang mengetahui tentang pemeriksaan payudara sendiri (SADARI) dengan kategori cukup dan ada 27 orang $(67,5 \%)$ responden yang melakukan tindakan pemeriksaan payudara sendiri dengan kategori kurang baik. Dari hasil penelitian tersebut maka diharapkan pihak sekolah, siswi, dan petugas kesehatan sekitar dapat berperan aktif dalam memberikan informasi mengenai pemeriksaan payudara sendiri (SADARI).
\end{abstract}

Kata Kunci:

\section{PENDAHULUAN}

\section{Latar Belakang}

Remaja merupakan masa peralihan dari masa kanak-kanak menuju dewasa. Pada periode ini remaja mengalami pubertas. Selama pubertas, remaja mengalami perubahan hormonal dan mengalami perubahan dramatis dalam bentuk perubahan fisik. Perubahan fisik yang terjadi pada remaja putri seperti pertumbuhan payudara , penumbuhan lemak, kemangatan organ reproduksi dan pertumbuhan rambut genitalia yang mengiringi masa pubertas pada remaja (Leli, 2012).

Salah satu organ yang berkembang pada remaja khususnya wanita adalah payudara. Wanita harus lebih peka dan mulai memperhatikan organ payudara secara khusus. Semakin dini mengetahui masalah yang terjadi pada payudara maka semakin awal deteksi kanker payudara dapat dilakukan. Pengobatan yang dilakukan pada stadium awal akan meningkatkan kemungkinan sembuh dan kemampuan bertahanpun menjadi jauh lebih besar. (Nisman, 2011).

Pemeriksaan payudara sendiri (SADARI) merupakan salah satu langkah awal deteksi dini untuk menemukan kanker payudara stadium awal yang akan lebih efektif jika dilakukan sedini mungkin, sebab $85 \%$ kelainan di payudara justru pertama kali dikenali oleh penderita. Prognosis kanker payudara tergantung pada tingkatan pertumbuhan, pada tumor ukuran kecil tindakan preventif diharapkan. Oleh sebab itu, lebih baik melakukan penanggulangan kanker payudara di titik beratkan pada deteksi tumor stadium dini yang biasanya berukuran kecil (Rasjidi, 2010).

Apabila tidak melakukan skrining atau deteksi dini dengan pemeriksaan payudara sendiri maka tidak akan mendapatkan temuan masalah kanker atau kelainan yang terjadi di payudara seperti memiliki sejumlah tanda yang menunjukkan ketidaknormalan pada payudara. (Olfah dkk, 2013)

Data WHO tahun 2012 memperkirakan prediksi peningkatan subtansif 19,3 juta kasus kanker per tahun pada tahun 2025 ke depan, sehingga menyebabkan pertumbuhan dan penuaan global populasi semakin pesat. Pada tahun 2012 terdiagnosis 1,7 juta perempuan menderita kanker payudara dari 6,3 juta wanita (WHO, 2012)

Berdasarkan Sistem Informasi Rumah Sakit (SIRS) pada tahun 2010, di Indonesia kanker menjadi penyebab kematian nomor 3. Sementara itu, kanker payudara dan kanker leher rahim merupakan jenis kanker tertinggi pada pasien rawat inap maupun rawat jalan di 
seluruh RS di Indonesia, dengan proporsi sebesar 28,7\% untuk kanker payudara dimana merupakan proporsi terbesar pada penyakit kanker (KemenKes, 2013).

Masalah dalam penanggulangan kanker payudara di Indonesia adalah penderita datang ke pelayanan kesehatan sudah dalam stadium lanjut. Sumatera Utara melaporkan penderita yang berobat pada stadium dini hanya berkisar 20-30\%. Sedangkan penderita yang datang pada stadium lanjut sebanyak $70 \%$. Menurut data di Divisi Bedah Onkologi RSUP H. Adam Malik Medan, terdapat 1.427 penderita kanker payudara pada kurun waktu 20112013 (Sari, 2015).

Salah satu cara yang dapat dilakukan untuk mengurangi angka kejadian kanker payudara dengan pemeriksaan payudara sendiri. SADARI perlu dilakukan ketika seorang wanita telah mencapai masa pubertas (remaja) dan mulai mengalami perkembangan pada payudaranya (Rasjidi, 2010).

Menurut Sutjipto, saat ini telah banyak ditemukan penderita kanker payudara pada usia muda 1 . seperti remaja, bahkan tidak sedikit remaja putri usia 14 tahun menderita tumor di payudaranya. Dimana tumor yang terjadi bisa menjadi kanker, bila tidak terdeteksi lebih 2 . awal. Meskipun tidak semuanya ganas, tetapi ini menunjukkan bahwa saat ini sudah ada trend gejala kanker payudara yang semakin tinggi di usia remaja (Lily, 2008).

Pada saat ini, banyak remaja Indonesia yang masih belum peka terhadap perawatan untuk payudaranya sendiri (SADARI), mereka lebih peka terhadap jerawat yang timbul di wajah daripada adanya gejala kanker 1 . payudara. Di balik ketidakpekaan itu, juga dilatar belakangi oleh kurang informasi dan kemauan untuk menggali informasi mengenai pencegahan kanker payudara ini. Selain itu program pemerintah yang saat ini juga belum terfokus pada promosi tentang pelaksanaan SADARI bagi remaja dan hanya fokus kepada pelaksanaan 2 . mammografi saja. Bukan hanya itu, teknik SADARI juga terasa masih awam karena masih sedikitnya jumlah wanita yang rutin melakukan SADARI setiap bulan (Hidayat, 2007).

Dari hasil penelitian Risnawati (2015) pada 3. remaja putri di Pondok Pesantren Rohmatillah menunjukkan mayoritas remaja tidak melakukan pemeriksaan payudara sendiri yaitu sebanyak 28 orang (80\%). Menurut hasil penelitian Siallagan (2010) menunjukkan bahwa sikap remaja putri di SMA Surya Nusantara Kota Tebing Tinggi yaitu 38 responden $(53,6 \%)$ pada kategori kurang. Kurangnya pengetahuan remaja putri terhadap SADARI berpengaruh terhadap dilakukan dan tidak dilakukannya SADARI.

Salah satu strategi untuk meningkatkan pengetahuan siswa terhadap kesehatan adalah melalui pendidikan kesehatan. Pendidikan kesehatan yang diberikan secara dini, akan memudahkan remaja mencapai sikap dan tingkah laku yang diinginkan yaitu sikap dan tingkah laku yang bertanggung jawab. Oleh karena itu, sebagai upaya preventif sekaligus promotif yang dapat memberikan gambaran gaya hidup sehat kepada remaja saat ini adalah dengan cara memberikan pendidikan kesehatan kepada remaja Indonesia (Notoatmodjo, 2010).
Berdasarkan survei pendahuluan yang dilakukan peneliti pada tanggal 9 Januari 2016 menunjukkan bahwa 10 dari 204 siswi di SMK Negeri 07 Medan terdapat 3 orang yang mengetahui SADARI dan 2 orang yang mengetahui tindakan SADARI. Didapat 7 orang tidak mengetahui SADARI dan 8 orang yang tidak melakukan tindakan SADARI. Hasil survei pendahuluan juga membuktikan bahwa mayoritas responden yang tidak mengetahui SADARI dan tidak mengetahui tindakan SADARI yaitu jurusan Administrasi.

Dari uraian di atas bahwa pentingnya pemeriksaan payudara sendiri (SADARI) pada remaja putri yang bertujuan untuk mengenal adanya tanda-tanda kelainan pada payudara maka peneliti merasa perlu untuk melakukan penelitian tentang "Gambaran Pengetahuan dan Tindakan Pemeriksaan Payudara Sendiri (SADARI) Pada Remaja Putri Di SMK Negeri 07 Medan Tahun 2016”.

\section{Tujuan Penelitian}

Untuk mengetahui bagaimana pengetahuan tentang pemeriksaan payudara sendiri (SADARI) pada remaja putri di SMK Negeri 7 Medan tahun 2016.

Untuk mengetahui bagaimana tindakan pemeriksaan payudara sendiri (SADARI) pada remaja putri di SMK Negeri 07 Medan Tahun 2016.

\section{Manfaat Penelitian}

Hasil penelitian ini diharapkan dapat memberikan manfaat yaitu :

Bagi SMK Negeri 07 Medan, diharapkan dapat digunakan untuk mengetahui tingkat pengetahuan pada remaja putri dan mensosialisasikan tindakan pemeriksaan payudara sendiri (SADARI) ini di SMK Negeri 07 Medan untuk mendeteksi adanya gangguan pada payudara.

Bagi Responden, diharapkan dapat menambah pengetahuan dan wawasan remaja putri tentang pemeriksaan payudara sendiri (SADARI) dan diharapkan dapat diimplementasikan dalam kehidupan sehari-hari.

Bagi Peneliti, sebagai bahan informasi atau sumber data bagi penelitian berikutnya dan bahan pertimbangan bagi yang berkepentingan untuk melakukan penelitian yang sejenis.

\section{METODOLOGI PENELITIAN}

\section{Jenis dan Desain Penelitian}

Penelitian ini menggunakan jenis penelitian deskriptif dengan desain penelitian pendekatan cross sectional.

\section{Lokasi dan Waktu Penelitian}

Penelitian ini dilakukan di SMK Negeri 07 Medan yang terletak di Jl.STM No.12 E Medan Amplas. Penelitian ini dilakukan pada bulan Desember 2015 sampai dengan Juli 2016. 


\section{Populasi dan sampel}

Populasi pada penelitian ini adalah remaja putri kelas X di SMK Negeri 07 di jurusan Administrasi dengan jumlah 240 orang. Alasan mengapa peneliti mengambil populasi dari jurusan Administrasi dikarenakan pada saat studi pendahuluan mayoritas yang belum mengetahui pemeriksaan payudara sendiri adalah jurusan Administrasi.

Perhitungan Jumlah Sampel

Rumus :

$$
\begin{aligned}
\mathrm{n}=-\frac{\mathrm{N}}{1+\mathrm{N}(\mathrm{e})^{2}} & \\
& =204 / 5,056 \\
& =40,34
\end{aligned}
$$

$=$ di bulatkan 40

Ket: $\quad N=204$

$$
\mathrm{e}=0,13
$$

Adapun teknik pengambilan sampel yang diambil oleh peneliti pada setiap kelas ialah dengan menggunakan teknik simple random sampling. Cara pengambilan secara simple random sampling dengan menggunakan undian yang diambil dari nomor absen siswa remaja putri kelas $\mathrm{X}$ di SMK Negeri 07 Medan.

Sampel dalam penelitian ini adalah siswa remaja putri kelas X jurusan Administrasi di SMK Negeri 07 Medan. Sampel harus memenuhi kriteria inklusi dan ekslusi.

a. Kriteria Inklusi

1) Hadir pada saat penelitian

2) Sudah haid

3) Siswi kelas $\mathrm{X}$ Jurusan Administrasi di SMKN 7 Medan

4) Bersedia menjadi responden

b. Kriteria Eksklusi

1) Tidak hadir pada waktu penelitian

2) Tidak bersedia menjadi responden

\section{Hasil Penelitian}

1. Pengetahuan tentang Pemeriksaan Payudara Sendiri (SADARI)

Tabel 1 Distribusi Pengetahuan tentang Pemeriksaan Payudara Sendiri (SADARI) Di SMK Negeri 07 Medan Tahun 2016

\begin{tabular}{llll}
\hline No & Pengetahuan & F & $\%$ \\
\hline 1. & Baik & 14 & 35 \\
2. & Cukup & 22 & 55 \\
3. & Kurang & 4 & 10 \\
\hline & Total & 40 & 100 \\
\hline
\end{tabular}

Berdasarkan table 1 diketahui bahwa ada 22 orang $(55 \%)$ responden yang tingkat pengetahuannya kategori cukup dan ada 4 orang $(10 \%)$ responden yang tingkat pengetahuannya kategori kurang.
2. Tindakan Pemeriksaan Payudara Sendiri (SADARI)

Tabel 2 Distribusi Tindakan Pemeriksaan Payudara Sendiri (SADARI) Di SMK Negeri 07 Medan Tahun 2016

\begin{tabular}{llll}
\hline No & Tindakan & F & $\%$ \\
\hline 1. & Baik & 13 & 32,5 \\
2. & Kurang Baik & 27 & 67,5 \\
\hline & Total & 40 & 100 \\
\hline
\end{tabular}

Berdasarkan tabel 2 diatas diketahui bahwa ada 27 orang $(67,5 \%)$ responden yang tindakan pemeriksaan payudara sendiri kategori kurang baik.

3. Pengetahuan dan Tindakan Pemeriksaan Payudara Sendiri (SADARI)

Tabel 3 Distribusi Pengetahuan Berdasarkan Tindakan Pemeriksaan Payudara Sendiri (SADARI) Di SMK Negeri 07 Medan Tahun 2016

\begin{tabular}{llllllll}
\hline & & \multicolumn{5}{c}{ Tindakan } & \multirow{2}{*}{ Total } \\
\cline { 3 - 7 } No & Pengetahuan & \multicolumn{2}{c}{ Baik } & \multicolumn{4}{c}{ Kurang } \\
& & & \multicolumn{5}{c}{ Baik } \\
\cline { 3 - 7 } & & F & $\%$ & F & $\%$ & F & $\%$ \\
\hline 1 & Baik & 5 & 35,7 & 9 & 64,3 & 14 & 100 \\
2 & Cukup & 8 & 36,4 & $\mathbf{1 4}$ & $\mathbf{6 3 , 6}$ & 22 & 100 \\
3 & Kurang & - & - & 4 & 100 & 4 & 100 \\
\hline & & 13 & 32,5 & 27 & 67,5 & 40 & 100 \\
\hline
\end{tabular}

Berdasarkan tabel 3 diatas diketahui bahwa ada 14 orang $(63,6 \%)$ responden yang mempunyai pengetahuan cukup dan tindakan pemeriksaan payudara sendiri (SADARI) kurang baik.

\section{Pembahasan}

\section{Pengetahuan Tentang Pemeriksaan Payudara Sendiri (SADARI)}

Berdasarkan Data diatas dapat dilihat bahwa responden yang mengetahui pemeriksaan payudara sendiri (SADARI) yang pengetahuannya baik berjumlah 14 orang (35\%), pengetahuan cukup 22 orang (55\%) dan pengetahuan kurang 4 orang (10\%). Hal ini menunjukkan meski sebagian besar pengetahuan pada remaja putri di SMK Negeri 07 Medan sudah cukup dan baik tetapi masih ditemukan adanya pengetahuan yang kurang yaitu berjumlah 4 orang (10\%). Keadaan ini menjelaskan bahwa masih ada remaja putri yang tidak mengetahui pemeriksaan payudara sendiri.

Pengetahuan yang kurang ini dapat dipengaruhi oleh beberapa faktor yang mana pada penelitian ini ditemukan faktor dari sumber informasi yang berasal dari orang tua/keluarga yang berjumlah 27 orang $(67,5 \%)$ yang sangat memiliki peran besar dalam memengaruhi pengetahuan remaja putri di SMK Negeri 07 Medan. Hasil penelitian ditemukan bahwa banyak remaja putri tidak mengetahui posisi yang benar pada saat melakukan pemeriksaan payudara sendiri (SADARI) sehingga dibutuhkan informasi yang lebih memadai untuk meningkatkan pengetahuan remaja putri tentang 
pelaksanaan pemeriksaan payudara sendiri (SADARI) dengan posisi yang tepat dan sesuai.

Hal ini sejalan dengan hasil penelitian Nursanti (2013) tentang pemeriksaan payudara sendiri (SADARI) pada remaja di Universitas Pendidikan Indonesia yang menunjukkan bahwa dari 87 responden ada $69 \%$ responden yang memiliki pengetahuan cukup dimana dipengaruhi oleh faktor memperoleh pengetahuan yaitu sumber informasi yang didapat masih minim. Demikian juga ditemukan sejalan dengan penelitian Yunus (2013) di SMA Negeri 4 Gorontalo tentang pemeriksaan payudara sendiri (SADARI) bahwa mayoritas ada pada kategori pengetahuan cukup sebanyak 107 orang $(73,3 \%)$ didapat bahwa pengetahuan remaja putri dipengaruhi oleh faktor lingkungan dan sumber informasi yang didapatkan. Pada hasil penelitian ini ditemukan bahwa remaja putri masih memiliki pengetahuan yang cukup dikarenakan kurang memahami langkah-langkah dalam pelaksanaan pemeriksaan payudara sendiri (SADARI).

Pemeriksaan payudara sendiri (SADARI) sebagai upaya pencegahan kanker payudara merupakan langkah dini yang harus diketahui oleh remaja putri sehingga pengetahuan mengenai pemeriksaan payudara sendiri (SADARI) merupakan hal yang sangat penting. Orang tua/keluarga merupakan lingkungan pertama untuk mendapatkan pengetahuan/pendidikan. Hal ini sesuai dengan pendapat Riamin (2016) yang menyatakan keterlibatan orang tua pada pendidikan sangat penting terbukti dari banyaknya dampak positif bagi anak khususnya remaja putri. Dalam keluargalah remaja putri dipersiapkan untuk membangun pengetahuan tentang perkembangan termasuk perkembangan fisik agar remaja putri mampu memasuki fase perkembangannya dunia lainnya seperti dunia orang dewasa, bahasa, adat istiadat dan kebudayaan.Namun ada beberapa factor lain yang menyebabkan minimnya informasi yang didapat dari orang tua antara lain: orangtua terlalu sibuk pada pekerjaannya, broken home, kondisi ekonomi kurang, kurang kesadaran orang tua terhadap pentingnya pendidikan bagi pengetahuan remaja putri.

Diketahui dari hasil wawancara dengan remaja putri di SMK Negeri 07 Medan bahwa para remaja merasa malu dan masih menganggap bahwa membicarakan hal yang berhubungan dengan masalah kesehatan wanita khususnya payudara tidak pada orang terdekat merupakan suatu hal yang tabu.

\section{Tindakan Remaja Putri Dalam Pelaksanaan Pemeriksaan Payudara Sendiri (SADARI)}

Berdasarkan data diatas diketahui bahwa responden yang tidak melakukan tindakan pemeriksaan payudara sendiri dengan kategori baik berjumlah 13 orang $(32,5 \%)$ dan kurang baik 27 orang $(67,5 \%)$.

Dari hasil penelitian menunjukkan bahwa meski pengetahuan remaja putri di SMK Negeri 07 Medan banyak yang cukup dan baik tetapi tindakan pemeriksaan payudara sendiri (SADARI) yang dilakukan remaja putri masih kurang baik dikarenakan remaja putri kurang menerapkan langkah-langkah pemeriksaan payudara sendiri (SADARI) secara tepat dan lengkap.
Hasil penelitian ini sejalan dengan Simanullang (2008) yang menyatakan bahwa respoden yang pernah melakukan SADARI sebanyak 70 orang $(40 \%)$ dan yang tidak melakukan SADARI sebanyak 105 orang (60\%) yang menunjukkan masih kurangnya minat responden dalam melakukan pecegahan kanker payudara dengan melakukan pemeriksaan payudara sendiri (SADARI).

Dalam pelaksanaan pemeriksaan payudara sendiri (SADARI) banyak diperoleh informasi dari orang tua/keluarga dikarenakan keluarga merupakan tempat pertama remaja putri mengenal dan mengetahui sesuatu sehingga orang tua/keluarga dituntut memilki wawasan yang luas terutama mengenai pemeriksaan payudara sendiri. Orang tua harus mampu mengimbangi rasa ingin tahu remaja putri mengenai perkembangan fisiknya khususnya pertumbuhan payudara sehingga orang tua tahu kapan harus mengenalkan dan mengajari remaja putri dalam melakukan tindakan pemeriksaan payudara sendiri. Menurut pendapat Oskamp dalam Neila (2008) menyatakan bahwa orang tua sangat besar pengaruhnya terhadap kehidupan anak-anaknya karena orang tua akan dijadikan role model bagi anak-anaknya. Hal tersebut berarti remaja tidak hanya perlu mengetahui tentang pemeriksaan payudara sendiri tetapi orangtua juga turut melakukan dan memberi contoh remaja putri dalam pelaksaan pemeriksaan payudara sendiri (SADARI). Jika orang tuanya saja tidak peduli dengan dilakukannya pemeriksaan payudara sendiri (SADARI) pada anaknya yang remaja, tentu remaja tersebut juga tidak peduli.

Hasil dari sebagian remaja putri yang ditanyakan, remaja putri yang tidak melakukan pemeriksaan payudara sendiri (SADARI) dikarenakan malas dan tidak sempat melakukannya karena pemeriksaan payudara sendiri (SADARI) yang memiliki banyak langkah dalam pelaksanaannya . Hal ini membuktikan bahwa remaja putri tidak termotivasi dalam melakukan pemeriksaan payudara sendiri (SADARI).

Keadaan ini menunjukkan bahwa masih minimnya pengetahuan remaja putri sehingga turut memengaruhi dilakukannya pemeriksaan payudara sendiri (SADARI). Hal ini tidak didukung oleh dengan pendapat Drucker (2004) yang mengatakan bahwa pengetahuan adalah informasi yang dapat merubah sesuatu atau seseorang; seiring dengan itu ia juga dapat mengarahkan kepada suatu tindakan, atau sesuatu yang dapat membuat seseorang mampu melakukan suatu tindakan yang berbeda secara lebih efektif. Oleh sebab itu pengetahuan mengenai pemeriksaan payudara sendiri (SADARI) tidak memengaruhi dilakukannya pelaksanaan pemeriksaan payudara sendiri (SADARI) dikarenakan beberapa faktor dalam pelaksanaan pemeriksaan payudara sendiri (SADARI) antara lain dikarenakan remaja putri merasa malas untuk melakukan pemeriksaan payudara sendiri (SADARI) dan tidak sempat karena terlalu banyak langkah dalam pelaksanaannya. Untuk itu dibutuhkan motivasi dan kesadaran diri yang kuat untuk dilakukannya pemeriksaan payudara sendiri (SADARI) pada remaja putri. 


\section{SIMPULAN DAN SARAN Simpulan}

Dari hasil penelitian ini yang dilakukan mengenai pengetahuan dan tindakan pemeriksaan payudara sendiri (SADARI) di SMK Negeri 07 Medan tahun 2016 dapat ditarik kesimpulan sebagai berikut :

1. Bahwa ada 22 orang $(55 \%)$ responden yang mengetahui pemeriksaan payudara sendiri (SADARI) yang pengetahuannya kategori cukup

2. Bahwa ada 27 orang $(67,5 \%)$ responden yang kurang baik dalam melakukan tindakan pemeriksaan payudara sendiri.

\section{Saran}

1. Bagi SMK Negeri 07 Medan

Diharapkan pihak sekolah SMK Negeri 07

Medan hendaknya meningkatkan pengetahuan siswa dengan memberikan informasi tentang SADARI misalnya melalui majalah dinding (Mading), buku-buku atau majalah kesehatan, dll.

2. Bagi Siswa

Agar siswa meningkatan pengetahuan dan tindakan pemeriksaan payudara sendiri (SADARI) dengan rajin mencari informasi dan mengikuti penyuluhan kesehatan tentang cara melaksanakan pemeriksaan payudara sendiri (SADARI) yang dilakukan di sekolah.

3. Bagi Pelayanan Kesehatan

Agar Pelayanan Kesehatan meningkatkan penyuluhan dan memberikan informasi tentang pemeriksaan payudara sendiri (SADARI) kepada masyarakat terutama pada SMK Negeri 07 Medan.

3. Bagi Peneliti

Hasil Penelitian ini dapat di jadikan sebagai bahan referensi untuk melanjutkan penelitian yang berhubungan dengan pemeriksaan payudara sendiri (SADARI) dalam mendeteksi sekaligus untuk mencegah penyakit kanker payudara pada remaja.

\section{DAFTAR PUSTAKA}

Arikunto, S. 2010. Prosedur Penelitian. Jakarta: Rineka Cipta

Hasibuan, R. 2014. Pengaruh Pengetahuan dan Motivasi Terhadap Sikap Remaja Putri yang Melakukan Pemeriksaan Payudara Sendiri (SADARI) Sebagai Upaya Deteksi Dini Kanker Payudara Di SMA Negeri 1 Marbau Kabuapten Labuhanbatu Utara. Skripsi. Tersedia di http://repository.usu.ac.id/bitstream/123456789/4 4355/7/babi.pdf. [Diunduh tanggal 25 Nopember 2015]

Hidayat, A. A. 2007. Metode Penelitian Kebidanan dan Teknik Analisa Data. Jakarta: Salemba Medika

Hidrah. 2008. Deteksi Dini Kanker Payudara. Jakarta: Ganesha

Kementrian Kesehatan Indonesia. 2013. Profil Kesehatan Indonesia Tahun 2012. Jakarta: Kementrian Kesehatan Indonesia.
Lily. 2008. Hati-Hati, ABG Rentan Terkena Kanker Payudara. [Online]. Tersedia di http://www. Rileks .com. [Diakses 12 Desember 2015]

Leli, Indida. 2012. Gambaran Pengetahuan Remaja Putri Tentang Perineal Hygiene Di SMPIT As Salam Pasar Minggu. Skripsi. Tersedia di http : // www.FIK UI. Com [ Diunduh 5 Desember 2015 ]

Mulyani, Nina Siti. 2014. Kanker Payudara dan PMS Pada Kehamilan. Jogjakarta: Nuha Medika

Nisman, A. W. 2011. Lima Menit Kenali Payudara Anda. Jogjakarta: Andi.

Notoatmodjo, Soekidjo. 2003. Pendidikan dan Perilaku Kesehatan. Jakarta: Rineka Cipta 2003. Metodologi Penelitian Kesehatan. Jakarta: Rineka Cipta 2007. Promosi Kesehatan dan Ilmu Perilaku. Jakarta: Rineka Cipta 2010. Metodologi Penelitian Kesehatan. Jakarta: Rineka Cipta

Nursalam. 2003. Konsep dan Prosedur Metodologi Penelitian Ilmu Keperawatan. Jakarta: Infomedika

Olfah Yustiana, dkk. 2013. Kanker Payudara dan SADARI. Yogyakarta: Nuha Medika

Pamungkas, Zaviera. 2011. Deteksi Dini Kanker Payudara. Yogyakarta: Buku Biru

Putra, Sitiatava Rizema. 2015. Buku Lengkap Kanker Payudara. Yogyakarta: Laksana

Putri, Arini Estiati. Hubungan Tingkat Pengetahuan dan Sikap Remaja Putri Terhadap Perilaku SADARI di MA KMI Diniyyah Puteri Padang Panjang. Skripsi Tahun 2011. [Online]. Tersedia di http://perpus.fkiki.uinjkt.ac.id/file digital/arini\%2 0estaiti\%20putri.pdf. [Diunduh tanggal 3 Desember 2015]

Rasjidi, Imam. 2010. 100 Question \& Answer Kanker Payudara Pada Wanita. Jakarta: Gramedia

Risnawati, Indah. 2015. Hubungan Tingkat Pengetahuan Tentang Pemeriksaan Payudara Sendiri (SADARI) dengan Praktik Pemeriksaan Payudara Sendiri (SADARI) Pada Remaja Putri di Pondok Pesantren Rohmatillah. Skripsi. [Online]. Tersedia di http: //ejournal.stikesmuhkudus.ac.id/index.php/karakter/ article/viewFile/208/149

Sari, Dilla Febria. 2015. Hubungan Pengetahuan, Sikap dengan Tindakan Sadari Sebagai Deteksi Dini Kanker Payudara Pada Mahasiswi di Fakultas Kesehatan Masyarakat USU. Skripsi. [Online]. Tersedia

di http://repository.usu.ac.id/bitstream/123456789/5 2137/7/babi.pdf. [Diunduh 3 Desember 2015]

Sarwono. 2006. Pengertian Remaja. Jakarta: Aneka Cipta

Sarwono. 2010. Psikologi Remaja, Edisi Revisi. Jakarta: PT Raja Grafindo

Siallagan, N.H., 2010. Perilaku Remaja Putri tentang Pemeriksaan Payudara Sendiri (SADARI) di SMA Surya Nusantara Kota Tebing Tinggi. Jurnal Akdemi Keperawatan Bina Husada 
Tebing Tinggi. Volume II No. 3. Online. Tersedia di

http://repository.usu.ac.id/bitstream/123456789/5 6968/5/Chapter\%20I.pdf. Diunduh tanggal 3 Desember 2015.

Sugiyono. 2012. Metode Penelitian Kuantitatif Kualitatif dan $R \& B$. Bandung: Alfabeta.

Widyastuti, Y. 2009. Kesehatan Reproduksi. Yogyakarta: Fitramaya

Wawan, A dan Dewi, M. 2010. Teori dan Pengukuran Pengetahuan, Sikap dan. Perilaku Manusia. Yogyakarta : Nuha Medika.
Wardiah. 2012. Periksa Payudara Sendiri (SADARI) Sebelum Terlambat. [Online]. Tersedia di http://www.alodokter.com/periksa-payudarasendiri-sadari-sebelum-terlambat. Diakses tanggal 1 Maret 2016

World Health Organization. 2012. The World Health Organization's Fight Against Cancer: Strategies That Prevent, Cure and Care. Tersedia di: http://www.who.int/cancer/modules Diakses tanggal: 1 Maret 2016. 